\title{
The Role of Individual Difference Factors in Writing Feedback Use and Involvement: A Qualitative Study of Iranian EFL Learners' Perceptions
}

\author{
Mahboobeh Saadat
}

Shiraz University, Iran

Saeed Mehrpour

Shiraz University, Iran

Yaser Khajavi*

Salman Farsi University of Kazerun, Iran

\section{Introduction}

Ever since the publication of the controversial paper by Truscott (1996) regarding the ineffectiveness of corrective feedback, research on corrective feedback has attracted a surge of interest on the part of a large number of researchers (e.g., Bitchener, 2008; Ellis, 2010; Hyland \& Hyland, 2006; Lee, 2008; Shintani, Ellis, \& Suzuki, 2014; Yu \& Lee, 2014). In fact, corrective feedback has been studied from different perspectives and many insights have emerged from these studies.

Lee (2007) holds that feedback needs to be investigated from the students' viewpoint in order to help teachers fine-tune their responses to students' needs. Moreover, Second Language (L2) researchers are greatly interested in studying how to provide feedback to student writing efficiently (McMartin-Miller, 2014). Although written corrective feedback (WCF) has been approached from different perspectives, there is a startling gap in the literature: "the lack of careful consideration of individual learner characteristics as they receive, process, and apply WCF" (Ferris et al., 2013, p. 308). Reminding researchers of this gap, Ferris et al. emphasize that "looking at student texts in isolation will not give researchers or teachers enough information about if/how/why WCF helps student writers improve (or does not). Rather, there must be careful consideration of the larger context, the classroom characteristics, the teacher, and the learners themselves" (p. 
324). In addition, research has shown that neglected individual differences such as First Language (L1) background, attitudes, and levels of motivation can influence the outcome of writing including CF largely (Kormos, 2012).

Although an impressive array of research has investigated the best ways to give feedback to student writing, Ellis (2009) accentuates that " $[\mathrm{t}]$ he search for the 'best' way to do written CF may in fact be fundamentally mistaken if it is accepted that $\mathrm{CF}$ needs to take account of the specific institutional, classroom, and task contexts" (p. 106). Several studies have referred to this shortcoming (e.g., Busse, 2013; Evans, Hartshorn, McCollum, \& Wofersberger, 2010; Yu \& Lee, 2014). Evans et al. (2010), for example, highlight the idea that instead of studying whether feedback is effective or not "researchers and teachers ought to contextualize research findings and pedagogical practice within the framework of learner, situational, and methodological variables" (p. 459).

Another concern with regard to research on $\mathrm{CF}$ is the predominant focus on quantitative studies. While quantitative studies have contributed to this line of research largely, it must be asserted that processes involved in applying feedback cannot be deeply examined through quantitative research (Liu \& Brown, 2015). This may be due to the complex nature of feedback and the ways students apply it in their writing. Therefore, the process of learning from feedback needs to be scrutinized in CF research. In line with the above-mentioned need, Hyland (2010) maintains that there is a paucity of research on how students are influenced by feedback and engage with it. Likewise, I Lee (2013) notes that little information is available on what happens in a real classroom after instructors provide responses to student errors.

Ellis (2010) defines 'engagement' as 'how learners respond to the feedback they receive" (p. 342). The process of student engagement has a critical role to play in writing. Hyland (2010) calls for longitudinal qualitative studies in order to investigate learning processes in natural classroom contexts. This type of research may allow us to delve deeply into students' perceptions of and engagement with different types of feedback.

Murphy (2000) appropriately refers to another missing link in research on writing: i.e. "what students make of their teacher's responses" (p. 82). As mentioned before, most of the studies on CF have mainly tried to find the best ways to give feedback, i.e., whether feedback should be direct, indirect, or metalinguistic. However, the fact that most of such studies neglect individual differences and, hence, sociocultural contexts may make their findings problematic. In fact, research in this area has striven to suggest some effective ways of giving CF without regard to the factors that may influence the outcome of student writing. Murphy challenges this trend noting that "depending upon the situation, the abilities of the students, and the ways students interpret our comments, our good intentions may not be met" 
(p. 84). She continues to suggest that "if we view learning as occurring in interactions in which individuals are actively engaged in constructing meaning, then the need to understand the learners' interpretation of our comments is critical" (p. 86).

Nevertheless, as far as research on writing and CF, especially in the Iranian context, is concerned we have scant published research in this area. It is expected that the current study may shed light on this under-researched area.

\subsection{Objectives of the Study and Research Questions}

The purpose of the present study is to investigate individual factors that mediate Iranian EFL students' engagement with feedback they receive on their writing. In fact, the purpose behind such a consideration is to identify the factors that may contribute to using or ignoring feedback by students. To fulfill the aims of the study, the following research questions were formulated.

1. What do Iranian EFL learners consider to be efficient feedback?

2. Why do the students sometimes ignore the received feedback?

3. What feelings and emotions do the students experience when receiving feedback?

\section{Literature review}

The current views of feedback mainly focus on the importance of students' agency arguing that the traditional feedback provided by teachers may result in the students' dependence on their teachers (Hawe\& Dixon, 2014). Besides, it has been claimed that in order to develop students' ability of evaluation and production, three conditions should be fulfilled: "students need to understand the goals of learning and what constitutes quality work, compare current performance to what is expected, and have a repertoire of strategies so they can modify performance as necessary" (Sadler, 1989, 2009, as cited in Hawe\& Dixon, 2014, p. 67).

Nicol (2010) also holds the same view arguing, "feedback should be conceptualized as a dialogical and contingent two-way process that involves coordinated teacher-student and peer-to-peer interaction as well as active learner engagement" (p. 503). Despite their extensive acceptance, such views have still remained at the theoretical level and have not found their way to writing classes in an appropriate and tangible manner. As far as teachers and students are concerned, Nicol (2010) notes that they are not satisfied with feedback procedures. In particular, teachers believe that their students do not take on board their provided feedback. Therefore, the view supporting the transmission process of feedback should change. That is, while the quality of feedback is important, the students' interaction with feedback that leads to learning is more essential. To put it another 
way, as written corrective feedback is a monologue, it cannot serve the dialogic purpose of learning.

Students' understandings of their use of feedback are very critical elements in research on feedback (Zhao, 2010). Thus, one vein of research has considered teachers and students' perceptions of feedback. Zhao (2010), for example, investigated Chinese EFL learners' perception of peer and teacher feedback. The study took 16 weeks during which three methods of stimulated recall, content analysis and interviews were applied. The results revealed that the students used more teacher than peer feedback. Further investigation, however, showed that these students used feedback without knowledge of its value. The researcher concludes that students' perceptions of feedback should be regarded as an important element in developing their writing proficiency.

On the other hand, although students' perceptions are intermingled with individual differences, CF studies taking individual differences into account are scarce. There have been some recent attempts at considering the role of individual differences in different contexts. Lee (2008), for example, examined the factors that affected Chinese secondary students' reactions to the feedback provided by their teachers. The data collected from students and teachers revealed that students preferred written comments. Moreover, low proficiency students were less interested in receiving feedback compared with more proficient ones. The researcher concluded that wants and attitudes of students need to be taken into consideration by teachers so that they can provide their students with proper feedback.

In another study, Storch and Wigglesworth (2010) explored engagement of students with direct and indirect feedback. The study aimed to find why some feedback turns into uptake but some does not. It took three sessions involving learners' pair work to write a text based on a graphic prompt (session 1), reviewing the feedback and rewriting the texts and receiving feedback either in direct or indirect form (session 2), and producing a text individually (session 3). The findings revealed that both linguistic and affective factors such as students' beliefs and attitudes could influence their uptake and retention. Accordingly, the researchers called for further research on CF taking affective factors into account.

In this line of research, Busse (2013) carried out a study from a motivational perspective and surveyed the perceptions of students on feedback in a German course at two universities based in the UK. The findings showed that the students regarded feedback as important because it led to the enhancement of their selfefficacy and motivation and in the absence of feedback, they reported feelings of unwillingness. Moreover, Ferris et al. (2013) investigated the individual/contextual factors that might affect students' use of CF. The analysis of case studies showed that individual factors such as confidence and attitude can influence students' benefitting from WFC. 
Moreover, from a rather different perspective, Shintani and Ellis (2013) studied how individual differences, language analytic ability (LAA) in this case, influenced learners' processing of different WCF and metalinguistic explanation. The results revealed that language analytic ability was effective in the processing of both metalinguistic and direct feedback. They also found that the influence of LAA is dependent on the "type of feedback, whether learners are asked to revise, and the nature of grammatical target" (p. 118). This study can be a starting point on the studies investigating the cognitive variables in relation to feedback.

Yet in another study, Best, Jones-Katz, Smolarek, Stolzenburg and Williamson (2014) studied the views of students in an advanced academic writing course. Semi-structured interviews were conducted to identify the students' perceptions of feedback. The findings revealed that the students' perceptions were heavily influenced by their grades and the teachers' comments which targeted their emotions and motivation. In addition, the students favored teacher feedback over peer feedback. The superiority of teacher feedback to peer feedback has been shown in many studies and even some studies revealed positive effect of teacher feedback on individual difference factors such as self-efficacy (e.g. Ruegg, 2014).

Finally, McMartin-Miller (2014) reported on a study investigating the attitudes of 19 international university students in a composition course. Specifically, the researcher strived to find if students favoured selective or comprehensive error feedback on their writing. The results showed that students preferred to receive comprehensive feedback while teachers preferred selective marking. It is interesting, however, that the students were also interested in the selective feedback by one of their favourite teachers. Nevertheless, the scope of the study was too limited to thoroughly explore the students' attitudes as it merely incorporated their attitudes towards direct and indirect feedback, excluding affective factors. As the above literature review shows, research on the interaction between individual differences and writing feedback is still at its infancy and there is still much to be learned in this area.

\section{Method}

\subsection{Context of the study}

The study was conducted at an Iranian state university. Founded in 1955, it was one of the oldest universities of Iran. The university has 14 faculties, 53 departments, and about 500 faculty members. The English Department has 11 full time members; however, each semester some part time instructors may also be recruited to teach in the department. The university runs MA and Ph.D. programs in TEFL. In addition, English Literature courses are offered to the students in the BA and MA programs. As for cultural characteristics of the students at the university, they have some characteristics in common such as native language; 
however, there are also some differences because of the variety in the ethnicity as well as the family background of the students. Very much like some of the universities in Iran, the majority of students in this university are females.

\subsection{Participants}

An intact class was observed over two consecutive semesters when they were taking the two writing courses, Basic Writing and Advanced Writing taught by two different instructors. A convenient sample of 10 undergraduate students was recruited from an intact writing class in which students were usually provided with different types of feedback in both oral and written forms. It is worth mentioning that at first 15 students were randomly selected to participate in the study and caution was exercised to take the number of female and male students into account by including an equal number of each gender group. However, five students quit the study at the outset of the interviews. The participants ranged in age from 19-36 years. In fact, the participants were BA students of English Literature who were supposed to take two writing courses, Basic Writing and Advanced Writing taught by two different instructors, offered consecutively as compulsory courses in the BA program. The pseudonyms of the ten student participants were: Farid, Ghazaleh, Sara, Hashem, Hussein, Maral, Nadi, Ghazal, Amir, and Younes.

\subsection{Instruments}

Semi-structured interviews were conducted with the students from the outset of the writing classes (every four sessions) in the form of focused-group interviews. The purpose of conducting these interviews was gaining insights into the students' attitudes and motivation in the writing class in general and regarding CF they received in particular. In addition, through semi-structured interviews, it was possible to ask questions which could not only elicit the students' attitudes but also provide room for their further comments.

However before conducting the interviews, in line with the aims of the study, some interview schemes were developed. To design these schemes, the literature on the topic was reviewed carefully several times and the relevant information was extracted. All the interviews with the students and the instructors were conducted in Persian so that they would be more comfortable in the discussions and focus on the content rather than language. Indeed, the participants' speaking proficiency was not the focus of the study and conducting interviews in Persian was not in contradiction with the aims of the study. The students' comments were transcribed verbatim and were then translated with great fidelity in order to keep their original tone.

\subsection{Data collection procedures and analysis}

The researcher explained the general aim of the study and the task that the participants were to perform i.e. regular participation in the interview sessions. In order to maximize the students' cooperation, they were told that they would be paid 
based on the time they devoted to the study. The first interview session was conducted in the form of focused group interviews. The participants were ensured that the information they provided would be kept strictly confidential. In other words, the students were ensured that none of the university authorities including their instructors would be informed about their views regarding the courses and their names would be replaced by pseudonyms in the report of the study. The participants were interviewed in two groups of five. Each of them answered the retrospective questions and was allowed to discuss the answers given by other interviewees too. This sometimes led to open-ended discussions resulting in hot debates that were quite illuminating. The interviewer (the third author), did not inject his ideas into the students' mind and tried to be impartial as much as possible. In so doing, he avoided expressing his own ideas for or against the raised opinions. The whole interviews were tape-recorded. Data gathering through the interviews was continued up to the point of data saturation.

The data gathered from the interviews with the students were first transcribed. Then basic interpretive analysis and grounded theory which involve different types of data coding (Ary, et al., 2010) were applied to uncover the general pattern of the data. This involved classification of the data gathered into different themes and categories presented in the results of the study below.

\subsection{Analytical Framework}

Ellis's (2010) framework for investigating oral and written CF was used to examine the issues addressed in this study (see Figure 1). The framework will be briefly introduced below.

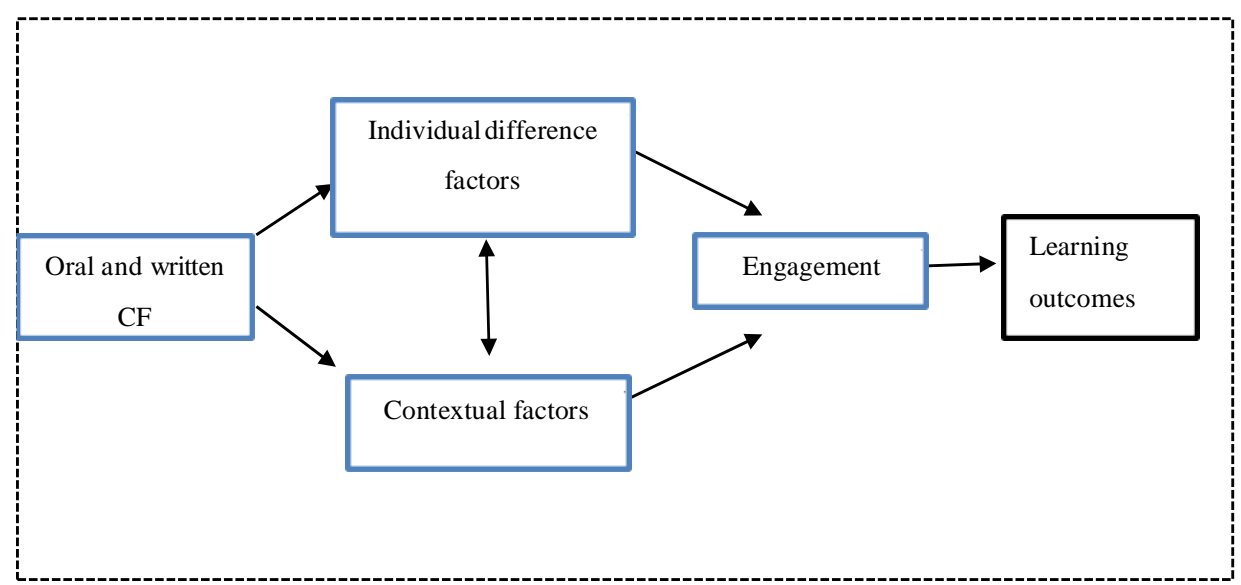

Figure 1: A componential framework for investigating CF (Ellis, 2010, p. 337)

As Ellis and Shintani (2013, p. 274) explain, this framework includes the following elements:

1. The different types of $\mathrm{CF}$ 
2. The role played by individual learner factors in mediating the effects of CF.

3. The role played by contextual factors in mediating the effects of CF.

4. The extent to which learners engage with the CF (i.e. how they respond to it).

5. Learning outcomes (i.e. the effect CF has on learning).

Based on this framework, individual difference factors and contextual factors mediate between the input received by learners and their engagement, which in turn leads to learning outcomes. According to Ellis (2010), "Individual learner factors include age, language aptitude, memory, learning style, personality, motivation, language anxiety, and learner beliefs" (p. 339). The researcher adopted an exploratory approach exploring the effective factors in students' ignoring or benefitting feedback through a qualitative emergent design.

\section{Results and Discussion}

In this section, results of data analysis are presented with reference to the emerging categories and themes related to the research questions.

\subsection{RQ1: What do Iranian EFL learners consider to be efficient feedback?}

Given the importance of learner beliefs in education, language educators need to plan and conduct learning programs considering students' perceptions and beliefs (Elwood \& Bode, 2014). Although, it would not be logical to decide on teaching methods solely based on students' views, their perceptions surely form a part of the learning puzzle, which needs to be taken into consideration. Figure 1 shows the main categories of the students' perceptions about efficient feedback that emerged from their interviews. 


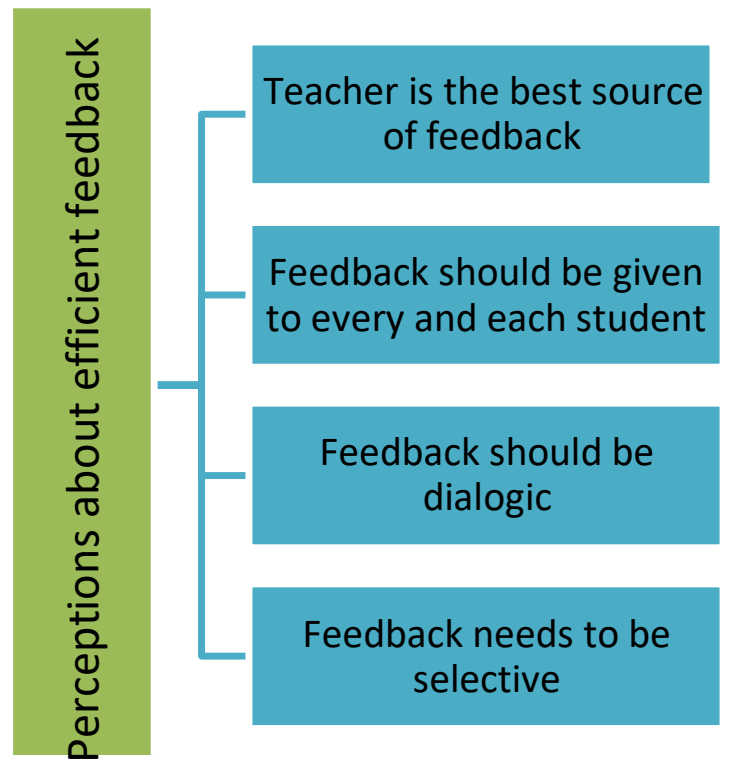

Figure 1: Students' perceptions about efficient feedback

\subsubsection{Teacher is the best source of feedback}

Almost, all the students favored teacher feedback over peer feedback. Even those who liked to receive feedback from peers were interested in receiving feedback from their teachers as a complement. Ruegg (2015) considers this finding not unexpected holding that "it is not surprising that when faced with peer and teacher feedback, students would pay more attention to teacher feedback. After all, it is the teacher who will evaluate the writing once it is submitted" (p. 2).

The students believed that someone who is the most competent of all in a class (i.e. the teacher) should give feedback to students. They did not consider students reliable sources of feedback. In addition, they held that it is the teacher who finally assesses them. Therefore, they asked, "What is the benefit of peer feedback?" This is in line with the findings of the study done by Guardado and Shi (2007) and is in contrast with those of Lee (2007) which indicated that students were interested in receiving peer feedback. This can be interpreted in light of the cultural background and previous educational background of the students. To put it aptly, Iranian EFL students do not extensively work in groups or as peers from elementary through high school education and this background might influence their perceptions regarding peer feedback. Peer feedback, despite its advantages, is affected by a number of factors such as students' cultural background and their language proficiency (Liu \& Hansen, 2002; Guardado\& Shi, 2007). 
In addition, students related success or failure of a writing course to factors including the quality of feedback provided by teachers.

\begin{abstract}
Mr. Naderi [the instructor] is not committed to the [students' learning] in class. In fact, I expected more. I have not learned anything more than what Ms. Tamadon [the instructor] taught us. The instructor just asks us to write paragraphs but does not return the corrections to us. He has not indicated where we have problems. Most corrections were in the form of correction in a sentence correction that we asked him to comment on. [Excerpt 1]
\end{abstract}

Another student also confirmed this shortcoming, stating "I need to know where my problems are because correction is very important. We need not only to write paragraphs but also to be corrected". Students definitely need and like to receive feedback from their teachers. The main reason is that they want how much they have learnt. Another reason may be related to the nature of writing; that, it is not usually possible to check one's writing without someone else's help whereas students can simply check their pronunciation or vocabulary knowledge through dictionaries on their own. When they do not receive feedback on their writing, they feel that they have not received due attention from their teachers and might be demotivated. This finding is in line with previous research that shows the importance of CF to students and the fact that they were happy with receiving it (e.g., Elwood \& Bode, 2014). However, despite the importance of CF, the students in this study seemed to receive little feedback on their work. Even some of them maintained that the received feedback was almost nothing.

As for the value of teacher feedback, Ruegg (2015) found that teacher feedback was more specific than peer feedback which was more direct. However, peer feedback resulted in more successful uptake. Surprisingly, teacher feedback, which was mostly indirect, created misunderstanding. As such, the researchers suggest that peer reviewers receive training on how to provide specific feedback to increase the uptake of students.

As the students reported, one procedure the teacher used to give feedback to the students was that he selected one sentence typical to the class, discussed it in front of the class, and elaborated on ways to improve it. Only one student, Nadi, confirmed this technique stating that "this strategy is quite useful because the students are mostly at the same level and when a problem is detected, it is most probably a common mistake". Nadi held that "explanation is very important as I can detect the reasons for the problems". She added that at the beginning, writing was appalling but now after learning new rules like how to write a topic sentence, she could do it easily. This shows that in the earlier stages of learning some students are anxious about how to write because of their scarce practice in 
developing this skill; however, after some sessions and receiving some feedback from their teacher, they will become more accustomed to the class and this skill.

\subsubsection{Feedback should be given to every and each student}

Students liked to receive feedback individually.Almost all the interviewees believed that feedback should be given to the students individually. They held that individual feedback would lead them to focus on their problematic areas and improve them. Nevertheless, the feedback they received was largely in the form of conferencing )i.e. collective feedback); while there was occasional individual feedback, it was not sufficient to cater for the students' needs. Scarcity of individual feedback could be mostly attributable to the time limitation of the class and large number of students. Although such limitations are parts of reality and cannot be avoided by teachers, students still demand the best education they deserve. In fact, personalizing teaching can be quite efficient in tailoring teaching to the students' needs. This is especially obligatory in the non-homogenous classes where students ask for different teaching input based on their needs and abilities.

As some of the students commented, feedback should be direct in the earlier stages, but indirect in later stages, and all the students confirmed the usefulness of feedback, stating that when one starts doing something for the first time, he needs to know where he is. When he understands in which area he has problems, he can correct it. Some of the students preferred direct feedback in this stage.

If the students could correct themselves, they didn't make mistakes. When you say this is problematic, many alternatives would be available. However, if the instructor suggests an alternative, it would be better. In the early stages, direct correction is better but later on indirect is better. Feedback should be given one by one. Some do not accept correction in front of the class. [Excerpt 2]

This finding can be interpreted with reference to the concept of learners' selfefficacy because in later stages when they are more proficient, they feel more selfefficacious and are, therefore, able to work independently correcting their errors.

\subsubsection{Feedback should be dialogic}

Most interviewees asserted that the teacher and the student should discuss the feedback and this dialogic relationship was very important to them. This type of feedback is missing in many instances due to the practicality issues. That is, writing classes are crowded and teachers have limited time to teach. As such, the writing teacher often cannot explain the reasons behind corrections. Alarge number of teachers even fail to provide the students with correction because of time limitations. As such, it is vital that teachers hold post feedback sessions with students and discuss the reasons for their corrections. The dialogic CF will lead to a deeper understanding of errors on the part of the student. This can be helpful to 
both teachers and students, as they will be familiarized with the sources of errors and the ways to avoid them as well.This finding was in line with Miao et al. (2006) who found that "teacher-initiated revisions are less successful than peer-initiated revisions, probably because negotiation of meaning during the peer interaction helps to enhance mutual understanding and reduces misinterpretation and miscommunication" (p. 193). This is also in agreement with Hawe and Dixon (2014) who suggest, " teachers establish an environment where students can freely exchange views about texts and mutually construct meaning in a thoughtful and reflective manner" (p. 69). The problem with the reported feedback in this context was that the teachers mostly acted as "error hunters" and the dialogic nature of feedback that could lead to the students' benefitting from feedback was ignored. AghajanzadehKiasi and Hemmati (2014) suggest that instructors "transform the individual written feedback on one student's writing to a Remedial Talk episode for all class, hence triggering [....] consequent awareness enhancement in a dialogically symmetric atmosphere" (p. 105).

\subsubsection{Feedback needs to be selective}

Students generally did not favor many red marks on their papers and felt embarrassed when receiving corrected errors. Therefore, they favored receiving feedback on the most vital issues rather than all problematic areas. This is in line with research on CF that supports selective CF (e.g., Bitchener, et al., 2005; Ellis, et al., 2008).

\section{2. $R Q$ 2: Why do students sometimes ignore the received feedback?}

Research shows that learning does not happen in a haphazard fashion; rather, it happens systematically and based on clear grounds. Regarding learning from feedback, "many writers have claimed that feedback can only be effective if learners pay attention to it (e.g. Chandler, 2003) and uptake of feedback in revision is one strong sign that a learner has paid attention to that feedback" (Ruegg, 2015, p. 3). In fact, the easiest way to see if feedback has been applied or not is to consider uptake. This is quite rational as several elements are involved in writing such as vocabulary, grammar and pragmatics which necessitate attention to feedback as an inevitable element. It is difficult to imagine that a student can apply the provided CF without sufficient attention. Therefore, teachers are to provide a situation that students take on board their corrections after paying attention to them. Nevertheless, this does not happen in some cases, which leads to the futility of feedback. The students in this study were questioned regarding the reasons that led them to ignore their teachers' feedback. The analysis of their responses resulted in the following categories (see Figure 2). 


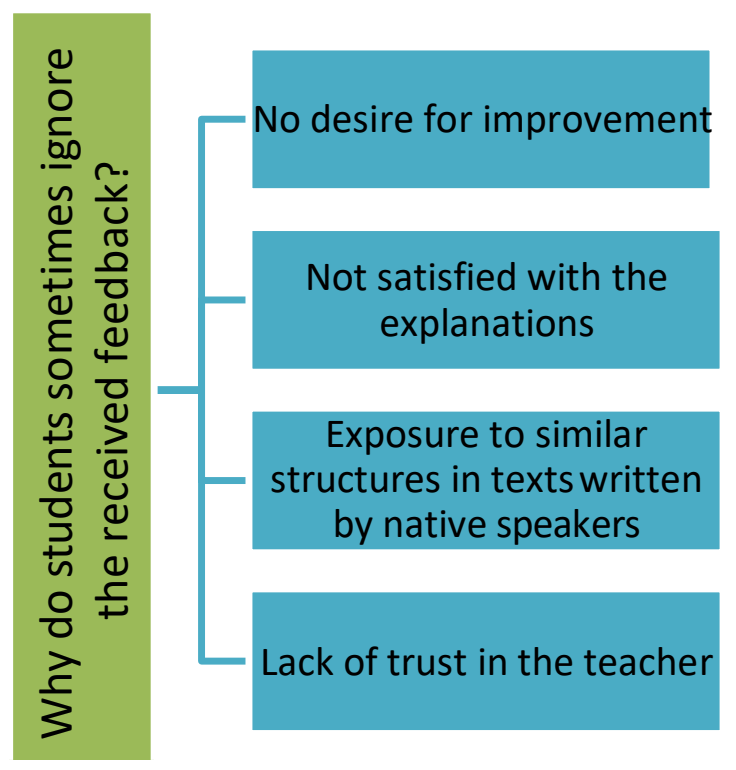

Figure 2: The reasons why students ignore feedback

\subsubsection{No desire for improvement}

The interviewees asserted that when they were not interested in learning something, they did not pay attention to the raised points or corrected structures.

When you don't like to improve, you don't pay attention to feedback but if you like to improve, you would like to get feedback and use it. Many of our classmates ignore feedback. ( Excerpt 3)

This is directly related to the motivational profile of the students. Learning does not happen automatically without persistent effort. This is especially applicable to learning how to write that needs much work and practice on the part of the students.This finding is in agreement with Uzum (2010) who found a relation between learners' intrinsic motivation and their production of uptake. However, it is in contrast with Askildson's (2008) study which rejected any relations between motivational profile of students and corrective feedback use.

Moreover, Gardner believes that motivation includes four elements: first, an individual should have a goal; second, s/he should have a desire to achieve it; third, the attitudes of the individual towards that goal should be positive. Finally, sufficient effort should be exerted to achieve that goal (MacIntyre, 2002). This finding is in line with the second elements in Gardner's taxonomy which is missing here. 


\subsection{Not satisfied with the explanations}

Most of the interviewees asserted that they did not have serious problems in understanding teacher feedback but they needed to be satisfied by teacher explanation. In fact, when the teacher's explanation was not convincing to them, they did not change their texts.

When I conclude that what I've written is better than what my teacher suggests, why should I change it? [Excerpt 4]

This is understandable in light of students' agency in selecting what to do with CF (Shepherd, O'Meara \& Snyder, 2016). It is the student who decides what to do with CF and can simply ignore it. In fact, if they consider CF not applicable, they simply ignore it. In this case, the problem that arises is that students neither mention their dissatisfaction with CF nor apply the feedback whereas the teachers expect the feedback to be applied.

There have been some instances that even I might have some problems in my writing which my teacher pointed them out but the teacher did not try to explain to justify corrected parts, and I couldn't understand his corrected points so I ignored them.

(Excerpt 5).

Another problem that can be inferred from what the students stated is that they consider the teacher to be solely responsible for providing $\mathrm{CF}$ and neglect their own role in inquiring about further explanation/justification. As a result, teachers' inadequate explanation and students' reluctance to shoulder the responsibility of seeking for justification would result in the inefficiency of the feedback the teacher provided on student writing. This can be attributed to the students' lack of autonomy. In fact, the participants did not report high levels of autonomy. They favored autonomy but asserted that, at the beginning levels, there should be some other-regulated strategies, i.e. they needed to be corrected. They did not feel confident enough to act independently in earlier stages. The students attributed their lack of autonomy to the shortcomings in their self-efficacy and proficiency.

\subsubsection{Lack of trust in the teacher}

Another important reason stated directly or indirectly by the students was lack of trust in the language teacher.

When I did not trust the knowledge of my instructor, I ignore his/her comments.Nevertheless, when I have low information in the areas that I am not that much proficient like writing I try to trust. [Excerpt 6] 
When students do not trust their teacher, they do not apply his/her comments simply because they do not regard them as positive and reliable. The origin of trust can be explained in both educational and psychological terms. Regarding the educational aspect, students should perceive the teacher as a knowledgeable person so that they can accept his/her comments. As for the psychological aspect, students should regard him/her as a person who is trying to help them learn how to write with good intentions.

The above excerpt shows that the knowledge of students is also a determining factor in their acceptance or rejection of teacher comments. That is, in some cases, students do not have positive attitudes towards their teachers but they accept teachers' comments because of their own low ability in a special skill or course. However, the extent to which the feedback is efficientis not evident. When it comes to writing, students mostly self-rate themselves at an elementary level mainly because of their low exposure to this skill in their educational experience.This will lead to accepting the instructor's feedback because of their low proficiency.

\subsubsection{Exposure to similar structures in texts written by native speakers}

Another point stated by the students was that they generally accept feedback if they have seen the corrected form in a text written by a native speaker.As Masood (2005) claims "the most effective way of improving writing skills is authentic materials, like newspaper editorials, columns, advertisements" (p. 39). The students considered native speakers to be models who serve as standards for determining correct English. Although this is correct to some extent, it sometimes happens that native speakers use a structure in an informal setting but students try to use it in a quite academic context. This can lead to confusion on the part of the students. In such situations, instructors need to explain clearly the differences between contexts to justify their corrections. Another important point is that language is not crystal clear and there can be some exceptions to a rule. Teachers should remind their students of this point to help them avoid future misunderstandings. In other words, while students' exposure to authentic texts is of importance to their language development, it can be confusing if they see a language structure or usage which is not in line with what their teacher taught them.

\subsection{RQ: What feelings and emotions do the students experience when receiving feedback?}

Emotions that students experience while/after receiving feedback can reveal which of the factors categorized as individual differences can influence their acceptance of and engagement with writing feedback. As such, the participants were asked questions regarding emotions that they had during and after receiving corrective 
feedback. Figure 3 shows the main themes that emerged from the students' interviews.

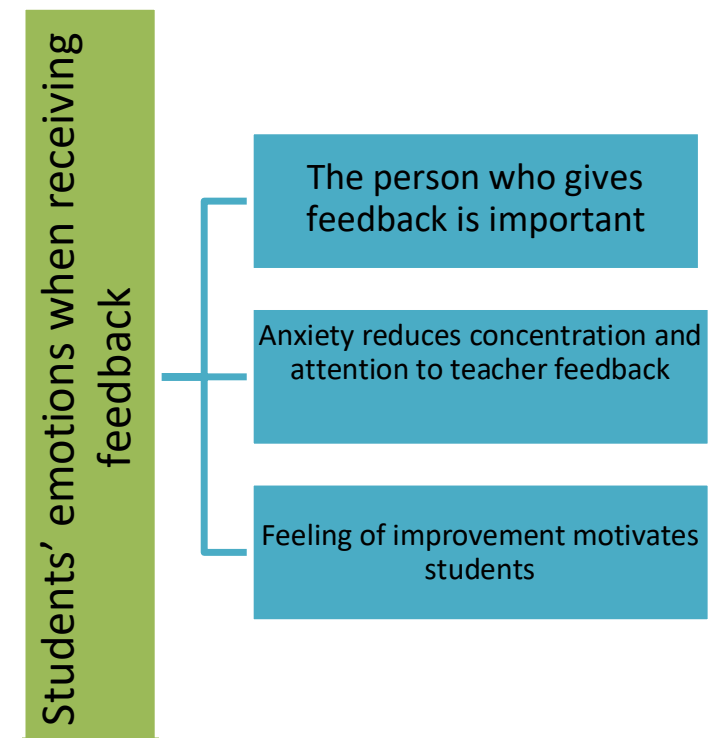

Figure 3: Students' emotions when receiving feedback

The students reported varying feelings when receiving feedback. Half of the interviewees reported happiness when they received feedback. Furthermore, they held that when they got feedback from their teachers, they could find the opportunity to become familiar with their possible shortcomings in writing and amend them. On the other hand, some reported feelings of pity when receiving feedback because they thought they knew the correct form and it was only because of lack of attention that they used the incorrect form. Therefore, they reiterated "Why did I make such a simple mistake?!". Some also reported embarrassment when receiving feedback. While a number of students felt uneasiness when receiving feedback at the beginning, they gradually felt relaxed when thinking about the advantages of $\mathrm{CF}$.

At first, I may become a bit unhappy but then happiness emerges when you think you've found your problem and you try to amend it. This is a step toward progress. [Excerpt 7]

Nevertheless, the point that was common among almost all of the students' comments on the emotions they experienced was related to the issue of who gives feedback. As they emphasized, the person who provided feedback was quite influential in forming the students' feelings and emotions. This idea will be clarified in the next section. 
Knoch et al. (2015) argue "the dynamics of affective engagement with WCF are also important" (p. 32). In fact, human beings are filled with positive and negative emotions that can influence every aspect of their lives including their education; learning from $\mathrm{CF}$, as a case in point, is not an exception.

\subsubsection{The person who gives feedback is important}

As mentioned, the interviewees reported that they considered some factors before accepting a comment. For example, they held that in addition to the knowledge, the intentions of the person who provides feedback were important to them. That is, the instructor should have good intentions to improve students' writing skill so that the feedback will be welcomed.

Feedback efficiency depends on who gives feedback. First, I should be sure that his knowledge is superior to mine. Then his/her intention should be correcting my mistakes not disparaging or mocking me. He should help me improve. Sometimes we do not like to even learn something from a person whom we don't like.

[Excerpt 8]

This excerpt from the students' interviews clearly shows the effect of emotional factors in accepting or rejecting CF. With respect to the motivational influence of feedback, the students believed that CF, when given properly, led to improvement not demotivation. This shows the role of students' attitudes in using or ignoring CF provided by the teachers.

It [CF] doesn't lead to demotivation; it leads to correcting yourself more and trying to follow teacher feedback. He [teacher] can tell us that our writing will be better. However, some areas are problematic and should be improve. [Excerpt 9]

The data gathered through the interviews revealed that the students had clear perceptions of the role of affective factors in their using or ignoring feedback and, thus, they insisted that the instructors should be careful about the affective load of their feedback. In other words, the instructors should not use words that may demotivate the students.

Correction should be accompanied by motivating words like "You will improve!", not with words such as "Don't you know such trivial points?!" This trivial mistake may be due to lack of attention and you may know the term. The teacher should not make students shocked by instant criticism. This may have negative effects. [Excerpt 10] 
As mentioned before, this extract shows that the students were highly cognizant of and attentive to the affective load of teacher comments and might be influenced by them willingly or unwillingly. In fact, their comments showed that they were generally highly influenced by teacher behavior in class.

\subsubsection{Anxiety reduces concentration and attention to teacher feedback}

Another important point raised by the students was that stress and anxiety led to their failure in using feedback. For example, one of the students declared that he had a high level of anxiety in comparison to the other students which deterred him from benefitting from feedback. Likewise, another student regarded the writing class stressful due to his lack of sufficient competence in this skill.

When I have stress, I cannot understand the feedback of the instructor and what he means. My stress was especially high in the writing class because I wasn't good at writing. [Excerpt 11]

As this extract shows, a high level of anxiety can be detrimental to the students' attention to feedback and subsequent learning. This student said that working with classmates reduced his stress as he liked group work more than individual learning. This may be due to the benefits of group work one of which is that students who have different capacities and responsibilities can cooperate and their cooperation leads to better performance. However, they also believed that sometimes students' pride led them to saying that "my idea is correct" and thus their rejection of the feedback.

Regarding the role of the teacher in this regard, the students mentioned that if the instructor provided feedback in an unfavorable manner, it led to their irritation and increased their level of anxiety. For example, one of the interviewees reported her experience of this feeling as follows:

I have a bit fear because he sometimes speaks disparagingly. This is something [writing] we are practicing for the first time; therefore, we don't have enough information about it. [Excerpt 12]

Another student clearly stated that he did not like to be judged by his teacher, which can be related to the anxiety he experienced after receiving negative feedback. He admitted that he tried not to make errors by avoiding complex structures.

Always I like to see fewer red comments [with laughter]. However, I like to be corrected soon. I write simple sentences to avoid errors and the professor is not able to detect my mistakes. The other day, he could detect just two errors which, unfortunately, were quite bad 
errors. I am happy in the class because I am involved in the activities. [Excerpt 13]

This quotation definitely shows that the students liked to be evaluated positively by their teachers and tried to avoid the anxiety provoked by teacher judgment. Another instance of the students' comments on their desire to avoid anxiety will follow.

Ms. Tamadon, for the purpose of comparing the learning level of students, tries to read some names from the list and ask them from the books exercises and waits for the answer at the same time. I think this method causes stress among the students because the person who cannot answer the question will feel a kind of disappointing and failure, especially in front of his or her classmates. [Excerpt 14]

Indeed, the above remarks, which provide evidence supporting the effect of students' anxiety on their performance, are all in agreement with Krashen's (1982) affective filter hypothesis.

\subsubsection{Feeling of improvement motivates students}

The students believed that instructors should offer hope to students because student's lack of hope leads to their demotivation. Teachers, for instance, should encourage students and assure them that they will learn how to write if they work hard.

When the instructor gives me feedback in a way implying that I will never learn how to write, I'll be disappointed.[Excerpt 15]

The interviews also revealed that the students evaluated their progress in line with the feedback they received and their self-evaluation of the efficiency of feedback resulted in their motivation/demotivation. In other words, sense of improvement was important to the students.

If the feedback is not appropriate and after some time I see that no improvement happens, I'll be disappointed. [Excerpt 16]

Another student also referred to the importance of the sense of improvement by stating that:

If after some time, I feel that I have not improved, it is disappointing. Or if we don't have time or think it [learning how to write] is farreaching because it's difficult. [Excerpt 17] 


\section{Conclusion}

The purpose of the present study was to investigate individual factors that mediate Iranian EFL students' engagement with the feedback they receive on their writing. The findings of the current study revealed that learning writing in general and using CF in particular did not happen in a linear fashion. That is, several factors that affected the whole process were involved in how to teach writing and provide feedback to students. The individual factors could influence the outcome of learning in a favorable or unfavorable manner.

More particularly, it was found that individual factors such as self-efficacy could definitely influence other factors such as motivation. When the participants felt that they were self-efficacious in writing, they tried to learn more and benefited from the instructors' feedback widely. Furthermore, the positive or negative feedback of an instructor could lead to changes in the students' attitudes towards learning writing or revising.

Another factor which had an important role to play was the goals that the students set for their learning. The findings of the study clearly revealed that the students interpreted the type of feedback provided as appropriate or inappropriate in light of their inner goals for writing. Whenever the feedback was in line with the students' inner goals, they interpreted it as informative. However, when it was in contrast with their goals and expectations, they regarded it as useless and ignored it.

In addition, the educational background of the students was of high importance. That is, because the students had limited, if any, practice in writing in the junior and senior high school level, they found it difficult to deal with this skill in the BA program particularly in the earlier stages. However, after writing some essays, they felt more comfortable with this academic skill.To conclude, the findings highlight the effective role of several factors which influenced the ways in which the students engaged with the provided CF and used or ignored it.

\subsection{Implications of the study}

Some implications can be enumerated based on the findings of the current study. The curriculum developers and officials need to consider students' individual differences and try to cater for such differences in one way or another; negligence of students' IDs can lead to their failure to learn how to write especially in academic settings. Kormos (2012) believes that the extent to which learners engage in learning tasks relevant to writing is dependent on motivational factors. She further suggests that for learners to involve deeply in doing writing tasks, they should have interest in language learning, high level of self-efficacy beliefs, goal orientation, attention to writing feedback, and involvement in revising their texts. 
The idea is clearly supported by the findings of the present study. That is, for students to start to engage in writing, a number of pre-requisites are obligatory. The first one is setting goals and then building sustainable motivation to engage and get involved in the tasks.

Furthermore, needs analysis regarding students' writing courses and their perceptions should be conducted regularly to determine the gaps and shortcomings of writing programs and the results should be shared with the instructors in order to let them know about the efficiency of their teaching so that they can gear their teaching towards amending the shortcomings and thus enhancing the efficiency of the courses. An interesting point concerning the source of feedback which is worth mentioning here is that students can receive corrective feedback from different sources including course books and the Internet. The participants in the present study all had access to the Internet but they rarely used it to correct their texts. Due to the great potential of the Internet to improve student writing, attempts should be made to take advantage of this amazing resource in correcting students' written output. However, currently, little (if any) instruction is provided to even student teachers on how to provide their future students with appropriate feedback.

As mentioned before, an important finding of the study was that whereas some of the interviewees believed that peer feedback could be helpful, almost all the participants believed that instructor feedback was superior to peer feedback. Therefore, it is suggested that even if peer feedback is applied in the writing class, the teacher should monitor and evaluate the final feedback. This would help students rely on the feedback provided and engage with it accordingly. In addition, in the case of peer feedback, for example, "awareness-raising is important for students from Asian countries where cultural norms may be antithetical to the pedagogical principles" (Hu, 2005, p. 332) of peer feedback. Discussion about the role of peer feedback, its benefits, its problematic aspects, etc. (Rollinson, 2005) can help raise students' awareness of the usefulness of peer feedback in the writing classroom. Teachers should go beyond acting the role of "error hunters". In fact, correcting students' errors is a process that starts with detecting students' errors. Then there should be a dialogic relationship to help learners correct their errors. Finally, a post CF phase should follow to monitor the students' progress. The dialogic nature of $\mathrm{CF}$ should be materialized in the education centers, whether universities or high schools, to enable teachers to achieve their goals in correcting students' errors.

In the writing workshops held for teachers, special attention should be devoted to $\mathrm{CF}$ and how to provide it effectively. In so doing, teachers, in particular, should become familiar with students' individual differences and how they may influence the students' benefitting from or ignoring CF. Teachers' basic knowledge of psychology will help in dealing with students' needs. In fact, while some teachers are familiar with psychological aspects of teaching/learning, those who are 
unfamiliar with such issues should be trained to take psychological factors into account when teaching writing and providing feedback.For example, it is suggested that teachers try to strengthen students' self-efficacy beliefs as they mediate between students and learning outcomes.

In such programs, student teachers need to particularly become familiar with different trends in correcting student writing. Besides pre-service programs, inservice ones also need special attention, as many teachers who have not received technical training on teaching writing and providing feedback are currently involved in teaching writing.

Given the limitations in teaching writing, chances for teachers to provide students with feedback become minimal. As such, instructors should try to include some alternatives for providing feedback. For example, there is some computer software which can edit the basic writing problems. Of course, this technology is in its embryonic stage but many teachers do not use even the current capacities in the Iranian context. Furthermore, the Internet can be a worthwhile option, which can be used in teaching writing widely. The use of the Internet also can revolutionize teaching writing and providing corrective feedback on student writing (Saadat, Mehrpour, \&Khajavi, 2016).

\subsection{Suggestions for further research}

Future research may consider each of the individual differences in relation to the development in various areas of writing. For example, future research can investigate how students' motivation can influence their accuracy development over time or in what ways students' self-efficacy beliefs may be related to the their writing proficiency. These studies would definitely provide the researchers with a more thorough picture of CF and its effects on individuals' writing.

\section{References and notes:}

Aghajanzadeh Kiasi, M., \&Hemmati, F. (2014). The importance of 'teacher talk' in teaching EFL writing. PortaLinguarum, 11, 95-108.

Ary, D., Cheser Jacobs, L., Sorensen, C., \&Razavieh, A. (2010).Introduction to research in education (8th ed.). Belmont, CA: Wadsworth, Cengage Learning.

Best, K., Jones-Katz, L., Smolarek, B., Stolzenburg, M., \& Williamson, D. (2015). Listening to our students: An exploratory practice study of ESL writing students' views of feedback.TESOL Journal, 6(2), 332-357.doi: 10.1002/tesj.152

Bitchener, J., Young, S., \& Cameron, D. (2005).The effect of different types of corrective feedback on ESL student writing.Journal of Second Language Writing, 9, 227-58.

Bitchener, J. (2008). Evidence in support of written corrective feedback. Journal of Second Language Writing, 17(2), 102-118. 
Busse, V. (2013). How do students of German perceive feedback practices at university? A motivational exploration.Journal of Second Language Writing, 22, 406-424.

Chandler, J. (2003). The efficacy of various kinds of error feedback.Journal of Second Language Writing, 12, 267-296.

Ellis, R. (2009). A typology of written corrective feedback types. ELT Journal, 63(2), 97107.

Ellis, R. (2010). Epilogue: A framework for investigating oral and written corrective feedback. Studies in Second Language Acquisition, 32 (2), 335-349. doi: 10.1017/S02772263109990544.

Ellis, R., \&Shintani, N. (2013).Exploring language pedagogy through second language acquisition research. UK: Routledge.

Ellis, R., Sheen, Y., Murakami, M., \& Takashima, H. (2008). The effects of focused and unfocused written corrective feedback in English as a foreign language context.System, 36(3), 353-371. Doi: http://dx.doi.org/10.1016/j.system.2008.02.001 Elwood, J. A., \&

Bode, J. (2014). Student preferences vis-à-vis teacher feedback in university EFL writing classes in Japan.System. 42, 333-343.

Evans, N. W., Hartshorn, K. J., McCollum, R., \&Wofersberger, M. (2010).Contextualizing corrective feedback in L2 writing pedagogy.Language Teaching Research, 14, 445463.

Ferris, D. R., Liu, H., Sinha, A., \&Senna, M. (2013).Written corrective feedback for individual L2 writers. Journal of Second Language Writing, 22, 307-329.

Guardado, M., \& Shi, L. (2007). ESL students' experiences of online peer feedback. Computer and Composition, 24, 444-462.

Hawe, E., \& Dixon, H. (2014). Building students' evaluative and productive expertise in the writing classroom.Assessing Writing, 19, 66-79.

Hyland, F. (2010). Future directions in feedback on second language writing: Overview and research agenda. International Journal of English Studies, 10 (2), 171-182.

Hyland, K., \& Hyland, F. (2006).Feedback on second language students' writing.Language Teaching, 39, 83-101.

Knoch, U., Rouhshad, A., Oon, S. P., \&Storch, N. (2015). What happens to ESL students' writing after three years of study at an English medium university?.Journal of Second Language Writing, 28, 39-52.

Kormos, J. (2012). The role of individual differences in L2 writing.Journal of Second Language Writing, 21, 390-403.

Krashen, S. D. (1982). Principles and practice in second language acquisition. Oxford: Pergamon.

Lee, E. J. (2013). Corrective feedback preferences and learner repair among advanced ESL students. System, 41, 217-230.

Lee, I. (2007). Feedback in Hong Kong secondary writing classrooms: Assessment for learning or assessment of learning? Assessing Writing, 12 (3), 180-198.

Lee, I. (2008). Understanding teachers' written feedback practices in Hong Kong secondary classrooms. Journal of Second Language Writing, 17(2), 69-85.

Lee, I. (2013). Research into practice: Written corrective feedback. Language Teaching, 46 (1), 108-119.

Lee, I. (2014). Revisiting teacher feedback in EFL writing from sociocultural perspectives.TESOL Quarterly, 48(1), 201-213.

Liu, Q., \& Brown, D. (2015).Methodological synthesis of research on the effectiveness of corrective feedback in L2 writing.Journal of Second Language Writing, 30, 66-81. 
Liu, J, \& Hansen, J. G. (2002).Peer response in second language writing classrooms. Ann Arbor: The University of Michigan Press.

Miao, Y., Badger, R., \& Zhen, Y. (2006). A comparative study of peer and teacher feedback in a Chinese EFL writing class.Journal of Second Language Writing, 15, 179-200.

McMartin-Miller, C. (2014). How much feedback is enough?: Instructor practices and student attitudes toward error treatment in second language writing. Assessing Writing, 19, 24-35.

Murphy, S. (2000). A sociocultural perspective on teacher response: Is there a student in the room?Assessing Writing, 7, 79-90.

Nicol, D. (2010). From monologue to dialogue: Improving written feedback processes in mass higher education. Assessment \& Evaluation in Higher Education, 35(5), 501517.

Ruegg, R. (2014): The effect of peer and teacher feedback on changes in EFL students' writing self-efficacy. The Language Learning Journal. doi:10.1080/09571736.2014.958190.

Ruegg, R. (2015). Differences in the uptake of peer and teacher feedback.RELC Journal.doi: 10.1177/0033688214562799.

Saadat, M., Mehrpour., S., \&Khajavi, Y. (2016). Internet-Mediated Corrective Feedback for Digital Natives.TESOL Journal, 7(1), 233-45.

Shepherd, R P., Daily O’Meara, K.,\& Snyder, S. E. (2016). Grammar Agreements: Crafting a More Finely Tuned Approach to Corrective Feedback. Journal of Response to Writing, 2(1), 43-57.

Shintani, N., Ellis, R., \& Suzuki, W. (2014).Effects of written feedback and revision on learners' accuracy in using two English grammatical structures.Language Learning, 64(1), 103-131.

Shintani, N., \& Ellis, R. (2013).The comparative effect of direct written corrective feedback and metalinguistic explanation on learners' explicit and implicit knowledge of the English indefinite article.Journal of Second Language Writing, 22, 286-306.

Storch, N., \& Wigglesworth, G. (2010).Learners' processing, uptake, and retention of corrective feedback on writing.Studies in Second Language Acquisition, 32(2), 303334.

Truscott, J. (1996). The case against grammar correction in L2 writing classes.Language Learning, 46, 327-369.

Yu, S., \& Lee, I. (2014).Understanding EFL students' participation in group peer feedback of L2 writing: A case study from an activity theory perspective.Language Teaching Research. [early view].1-22. DOI: 10.1177/1362168814541714.

Zhao, H. (2010). Investigating learners' use and understanding of peer and teacher feedback on writing: A comparative study in a Chinese English writing classroom. Assessing writing, 15(1), 3-17. http://dx.doi.org/10.1016/j.asw.2010.01.002. 


\title{
Summary
}

\section{The Role of Individual Difference Factors in Writing Feedback Use and Involvement: A Qualitative Study of Iranian EFL Learners' Perceptions}

\author{
Mahboobeh Saadat \\ Shiraz University, Iran
}

\author{
Saeed Mehrpour \\ Shiraz University, Iran
}

\section{Yaser Khajavi \\ Salman Farsi University of Kazerun, Iran}

\begin{abstract}
The purpose of the present study was to investigate individual factors that mediate Iranian EFL students' engagement with feedback they receive on their writing. In fact, the purpose behind such a consideration was to identify the factors that may contribute to students' using or ignoring feedback as well as the emotions they may have during or after receiving feedback. A convenient sample of 10 students was recruited from an intact writing class in which students were usually provided with different types of feedback in both oral and written forms. The study enjoyed a qualitative case study design. The findings of the focused-group interviews revealed that students favored selective, individual and dialogic feedback by the teacher. In addition, they ignored feedback when they were not interested to learn or when the person providing it was not of interest to them. Finally, they liked to receive feedback and anxiety reduced their uptake from the received feedback. The findings are discussed and implications are suggested in relation to teaching writing.
\end{abstract}

Key words: Individual difference factors, Writing Feedback Use,Learners' Perceptions 